\title{
Knowledge, attitude and practise of breast feeding among postnatal mothers at rural tertiary hospital
}

\author{
Haricharan $\mathbf{K} \mathbf{R}^{1}$, Vardhan $\mathbf{K}^{2}$, Naidu $\mathbf{R}^{3}$ \\ ${ }^{1}$ Dr. Haricharan K R, Associate Professor Paediatrics, ${ }^{2}$ Dr. Keerthi Vardhan, P.G. Resident, ${ }^{3}$ Dr. Rajendra Naidu, \\ Professor and HOD Paediatrics, all authors are affiliated with P.E.S. Institute of Medical Sciences and Research, \\ Kuppam, A.P, India.
}

Address for Correspondence: Haricharan K R, Associate Professor Paediatrics, PESIMSR, Kuppam, AP, Email: dr.haricharan@gmail.com

\begin{abstract}
Objectives: To assess the knowledge, attitude and practice of breast feeding among admitted postnatal mothers and to find out their relationship with socio demographic factors. Material and Methods: This was a prospective cross sectional study of 240 post-natal mothers admitted in rural tertiary care hospital. The study included a face to face interview of mothers using a pretested questionnaire and analysis of data using SPSS (version 20). Results: Majority $(n=201, \%=87.5)$ of mothers belong to age group of 18 to 26 with mean of 23.4 and standard deviation of 3.14 . Maximum (87.5\%) mothers belonged to Hindu religion. More than half of them were housewives (61\%) living in nuclear families and up to $40 \%$ of study population were employed. Majority of mothers from study group were primi - para (54.1\%). Prelacteal feeds were given by $16 \%$ and colostrum was discarded by $8 \%$ of mothers. About $80 \%$ of mothers were knowledgeable and likely to exclusive breast fed their babies. Antenatal counselling was received by $93.3 \%$ of mothers and majority of them by doctor $45.91 \%$. Significant association is seen with antenatal counselling (pvalue $<0.03$ ) and good breast feeding practises in post-natal mothers. Conclusion: Antenatal counselling promotes good breast feeding practises hence existing antenatal counselling on breastfeeding needs to be strengthened by informing all pregnant women about the benefits of breastfeeding and motivating them by curtailing their ill beliefs regarding breastfeeding and educating them that breast Feeding is the healthiest and safest way to feed babies.
\end{abstract}

Keywords: Breast feeding attitude, Knowledge, Practise, Sociodemographic factors

\section{Introduction}

Breast feeding provides nutritionally superior feed for the baby and is needed for survival and healthy growth $[1,2,3]$. It not only improves bonding and cognitive development, but also $[4,5,6]$ protects against diarrhoea, respiratory and other illness[7]. Benefits of breast feeding to mother include uterine involution, lesser risk of post-partum haemorrhage and protection against breast and ovarian cancer. Exclusive breast feeding causes lactation amenorrhoea and promotes proper birth spacing. Breast feeding should be initiated within half hour after normal delivery and within four hours after caesarean section. Based on evidence on the benefits of breastfeeding to the mother and baby, the World Health Organization (WHO) has recommended first 6 months exclusive breastfeeding and to continue breast feeding

Manuscript received: $28^{\text {th }}$ January 2017

Reviewed: $6^{\text {th }}$ February 2017

Author Corrected: $14^{\text {th }}$ February 2017

Accepted for Publication: $21^{\text {st }}$ February 2017 till 2 years of age [8]. In India, only $25 \%$ of new born are breast fed within an hour compared to nearby Sri Lanka where it is $75 \%$. National Family Health Survey (NFHS-3) data show proper initiation \& continuation of breast feeding in children under 6 months is just $46.4 \%$ [9]. Globally, $60 \%$ of infant and young child deaths occur due to inappropriate infant feeding practices. Two thirds of infectious disease related deaths are attributable to sub optimal breast feeding practices [10]. Inappropriate infant feeding practice could have negative effect on child growth and development, especially in developing countries, where accessibility of basic health services is not sufficient. Although breastfeeding is nearly universal in India, very few children are put to the breast immediately after birth. Ninety-six percent of children under age five have ever been breastfed, but only one-quarter of last-born children who were ever breastfed started breastfeeding within one hour of birth, as is recommended. Most 
mothers (57 percent) gave their last-born child something to drink other than breast milk in the three days after delivery. Prelacteal feeds were more common in rural areas than in urban areas and among women with no education. The factors that hinder the full realization of benefits of breast feeding include cultural beliefs, maternal characteristics, infant health problems, socioeconomic status, knowledge attitude and some psychological aspects. In spite of many awareness programs for pregnant and lactating women in particular and public in general, we still see many faulty breast feeding practices and hence there is an increased need to find the factors hampering breastfeeding. Hence the present study was undertaken with the objective to assess the knowledge, attitude and practise of breast feeding among postnatal mothers in rural tertiary care hospital at PES institute of medical sciences and research (PESIMSR) Kuppam.

\section{Methods}

This cross sectional study was carried out in PES Institute of Medical Sciences and research, KUPPAM for a period of 2 months from July 12016 to august 31
2016 after approval from institutional ethics committee. PESIMSR is a rural tertiary care medical college hospital of Andhra Pradesh bordering Tamil Nadu and Karnataka. The study population included 240 postnatal mothers admitted in the hospital. Mothers who were not willing to be a part of study and those with critical or psychiatric illness were excluded from the study. A face to face interview was conducted after delivery during second post-natal day using pretested questionnaire. The proforma included questions regarding knowledge, attitude and practise of breast feeding along with socio demographic details of study population. Data was summarized using descriptive statistics of frequency and percentages. The respondents rating of questionnaire of knowledge, attitude and practise was classified as good or poor based on their response. Chi square and Fischer exact test were used to test association between knowledge, attitude and practise with socio demographic factors. Fischer test was used if frequency was $<5$ and chi square if it was $>5$. The level of significance was set at $p<0.05$. Data were analysed with Statistical Package for Social Sciences (SPSS) software (version 20).

\section{Results}

Table-1: Socio-Demographic characteristics of studied population.

\begin{tabular}{|c|c|c|}
\hline Character & Group & Number (\%) \\
\hline Age & $\begin{array}{c}18-26 \\
>27\end{array}$ & $\begin{array}{c}201(83.75 \%) \\
39(16.25 \%)\end{array}$ \\
\hline Religion & $\begin{array}{l}\text { Christian } \\
\text { Hindu } \\
\text { Muslim } \\
\end{array}$ & $\begin{array}{c}2(0.83) \\
208(86.67) \\
30(12.50)\end{array}$ \\
\hline Education & $\begin{array}{c}\text { Illiterate } \\
\text { Secondary high school } \\
\text { High school } \\
\text { Graduate } \\
\end{array}$ & $\begin{array}{c}20(8 \%) \\
30(12.5 \%) \\
122(50.8 \%) \\
68(30.3 \%)\end{array}$ \\
\hline Occupation & $\begin{array}{l}\text { Housewife } \\
\text { Employee }\end{array}$ & $\begin{array}{c}145(60.4 \%) \\
95(39.6 \%)\end{array}$ \\
\hline Type of family & $\begin{array}{c}\text { Joint } \\
\text { Nuclear } \\
\text { Single parent } \\
\end{array}$ & $\begin{array}{c}84(35 \%) \\
153(63.75 \%) \\
3(1.25 \%) \\
\end{array}$ \\
\hline Parity & $\begin{array}{l}\text { Primi parous } \\
\text { Multi parous }\end{array}$ & $\begin{array}{l}130(54.1 \%) \\
110(45.8 \%)\end{array}$ \\
\hline Antenatal counselling & $\begin{array}{l}\text { No } \\
\text { Yes }\end{array}$ & $\begin{array}{c}16(6.7 \%) \\
224(93.3 \%)\end{array}$ \\
\hline $\begin{array}{c}\text { Antenatal counselling received } \\
\text { from }\end{array}$ & $\begin{array}{c}\text { Social health worker } \\
\text { Doctor } \\
\text { Nurse } \\
\text { Others }\end{array}$ & $\begin{array}{c}60(26.7 \%) \\
95(42.4 \%) \\
45(20.08 \%) \\
24(10.69 \%) \\
\end{array}$ \\
\hline Gestation at birth & $\begin{array}{c}\text { Term } \\
\text { Preterm }\end{array}$ & $\begin{array}{c}220(91.66 \%) \\
20(8.33 \%)\end{array}$ \\
\hline Type of delivery & $\begin{array}{c}\text { Vaginal } \\
\text { Caesarean section }\end{array}$ & $\begin{array}{l}136(56.6 \%) \\
104(43.3 \%)\end{array}$ \\
\hline Baby gender & $\begin{array}{c}\text { Male } \\
\text { Female }\end{array}$ & $\begin{array}{l}106(52.5 \%) \\
94(47.5 \%)\end{array}$ \\
\hline
\end{tabular}


A total of 240 mothers in postnatal ward delivered at PESIMSR Hospital, were enrolled for present study. The sociodemographic factors of studied population are depicted in Table 1.

Majority of them were in age group 18 to $26(83.75 \%)$ with mean age of 23.4 and standard deviation of 3.14. Most of the mothers belonged to Hindu religion (87.50\%) and were housewives (60.4\%) living in nuclear families $(63.75 \%)$. Almost $40 \%$ of mothers in study were employed. Majority of mothers from study group were primi - para (54.1\%). Almost $92 \%$ were term deliveries. The numbers of male and female babies delivered were almost same. The responses to important questions regarding knowledge, attitude and practise of breast feeding of study population are depicted in Table 2 .

Table-2: Knowledge, attitude and practise of breast feeding among post-natal mothers.

\begin{tabular}{|c|c|c|}
\hline Question & Response & Number $(\%)$ \\
\hline Best milk for baby & $\begin{array}{l}\text { Mothers } \\
\text { Cow } \\
\text { Infant formula } \\
\text { Don't know }\end{array}$ & $\begin{array}{c}230(95.83 \%) \\
2(0.8 \%) \\
2(0.8 \%) \\
6(2.5 \%)\end{array}$ \\
\hline Advantage of breast milk & $\begin{array}{l}\text { Only to baby } \\
\text { Only to mother } \\
\text { Both } \\
\text { None } \\
\text { Don't know }\end{array}$ & $\begin{array}{c}128(53.3 \%) \\
6(2.5 \%) \\
91(37.91 \%) \\
7(2.91 \%) \\
8(3.33 \%)\end{array}$ \\
\hline Pre lacteal feed to be given & $\begin{array}{l}\text { Yes } \\
\text { No }\end{array}$ & $\begin{array}{c}30(12.5 \%) \\
210(87.5 \%)\end{array}$ \\
\hline Aware of position and attachment of breast feeding & $\begin{array}{l}\text { Yes } \\
\text { No }\end{array}$ & $\begin{array}{l}211(87.91 \%) \\
29(12.08 \%)\end{array}$ \\
\hline Aware of signs of adequacy of feeding & $\begin{array}{l}\text { Yes } \\
\text { No }\end{array}$ & $\begin{array}{l}107(44.58 \%) \\
133(55.41 \%)\end{array}$ \\
\hline When did u initiate breast feeding? & $\begin{array}{c}\text { Within } 2 \mathrm{hrs} \\
6 \mathrm{hrs} \\
\text { 1day }\end{array}$ & $\begin{array}{c}223(92.9 \%) \\
6(2.5 \%) \\
11(4.58 \%)\end{array}$ \\
\hline How often do you breast feed your baby? & $\begin{array}{c}\text { Every } 2 \mathrm{hr} \text {. } \\
4 \mathrm{hr} \\
\text { Advice of family members } \\
\text { When child cries }\end{array}$ & $\begin{array}{c}150(62.5 \%) \\
36(15 \%) \\
6(2.5 \%) \\
48(20 \%)\end{array}$ \\
\hline Only breast milk up to & $\begin{array}{c}3 \text { months } \\
6 \text { months } \\
\text { Till I resume work } \\
\text { Family advice } \\
\text { till baby is sucking } \\
\text { Don't know }\end{array}$ & $\begin{array}{c}6(2.5 \%) \\
190(79 \%) \\
7(2.9 \%) \\
20(8.3 \%) \\
10(4.1 \%) \\
7(2.9 \%)\end{array}$ \\
\hline Did you discard the colostrum? & $\begin{array}{l}\text { Yes } \\
\text { No }\end{array}$ & $\begin{array}{c}13(5.41 \%) \\
227(94.58 \%)\end{array}$ \\
\hline
\end{tabular}

Majority $(95.83 \%)$ of mothers answered mothers' milk is best for baby. Most $(63 \%)$ of them were aware that breast feeding should be initiated within half an hour following vaginal delivery and 2 Hours in caesarian section. About $80 \%$ of the mothers knew that exclusive breastfeeding was giving only breast milk till 6 months of age. Most of the mothers 
(63\%) answered that they would feed every second hourly for the question regarding frequency of breastfeeding. Almost half of mothers (53\%) answered that breast feeding has advantage only to baby and only $20 \%$ of mothers were aware of advantage to both mother and baby. Majority of mothers answered that the major advantage of breast milk is providing nutrition to baby (54\%), but only $40 \%$ were also aware about maternal bonding and immunological benefits. More than two third $(88 \%)$ of mothers answered that prelacteal feeds should not be given and $43 \%$ of study population knew that baby sucking is the important stimulus for breast feeding. Though $88 \%$ of mothers knew about proper position and attachment for breast feeding, only $44 \%$ were aware of signs of adequacy of feeding. Nutritional superiority of breast feeding was known by $35 \%$ of mothers. In multi parous mothers prelacteal feeds was given to $16 \%$ of babies and majority of them had given cow's milk or honey. Colostrum was discarded by $8 \%$ of mothers in the study. About $10 \%$ of mothers in study group told they would stop breastfeeding once they resume work. Almost 75\% of multiparous mothers in the study had exclusively breast fed their last born babies. Antenatal counselling was received by $93.3 \%$ of mothers and majority of them by doctors $(45.9 \%)$.

About $36 \%$ of mothers told they encountered problems like breast engorgement, fatigue, back pain, nipple soreness, pain of caesarean section and child not sucking during breast feeding. Most common problem was the pain following caesarean section. Among the mothers who opted for formula feeding, commonest reason was the apprehension of inadequate breast milk.

Table-3: Analysis of association of sociodemographic characters with breast feeding practices.

\begin{tabular}{|c|c|c|c|}
\hline & \multicolumn{2}{|c|}{ Breast Feeding Practises } & \multirow[b]{2}{*}{ P VALUE } \\
\hline & $\begin{array}{l}\text { Good } \\
\text { N (\%) }\end{array}$ & $\begin{array}{r}\text { Poor } \\
\text { N }(\%)\end{array}$ & \\
\hline $\begin{array}{c}\text { Religion } \\
\text { Christian } \\
\text { Hindu } \\
\text { Muslim } \\
\text { Total }\end{array}$ & $\begin{array}{c}2(0.90) \\
191(86.43) \\
28(12.67)\end{array}$ & $\begin{array}{c}0(0.00) \\
17(89.47) \\
2(10.53)\end{array}$ & 0.880 \\
\hline $\begin{array}{c}\text { Education } \\
\text { Illiterate } \\
\text { Secondary high school } \\
\text { High school } \\
\text { Graduate }\end{array}$ & $\begin{array}{c}16(7.24) \\
29(13.12) \\
112(50.68) \\
64(28.96)\end{array}$ & $\begin{array}{c}4(21.1) \\
1(5.2) \\
10(52.6) \\
4(21.1)\end{array}$ & 0.153 \\
\hline $\begin{array}{l}\text { Occupation } \\
\text { Employee } \\
\text { Un employee }\end{array}$ & $\begin{array}{c}85(38.46) \\
136(61.54)\end{array}$ & $\begin{array}{c}10(52.63) \\
9(47.37)\end{array}$ & 0.226 \\
\hline $\begin{array}{c}\text { Family } \\
\text { Joint } \\
\text { Nuclear } \\
\text { Single parent }\end{array}$ & $\begin{array}{c}76(34.39) \\
142(64.25) \\
3(1.36)\end{array}$ & $\begin{array}{c}8(42.11) \\
11(57.89) \\
0(0.00)\end{array}$ & 0.717 \\
\hline $\begin{array}{l}\text { Parity } \\
\text { Multi } \\
\text { Primi }\end{array}$ & $\begin{array}{l}102(46.15) \\
119(53.85)\end{array}$ & $\begin{array}{c}8(42.11) \\
11(57.89)\end{array}$ & 0.734 \\
\hline $\begin{array}{c}\text { Antenatal Counselling } \\
\text { No } \\
\text { Yes }\end{array}$ & $\begin{array}{c}10(4.52) \\
211(95.48)\end{array}$ & $\begin{array}{c}3(15.79) \\
16(84.21)\end{array}$ & 0.037 \\
\hline
\end{tabular}

$P$ value $<0.05$ is taken as significant

Table 3 shows association of sociodemographic characters with breast feeding practises. Significant statistical association was seen with antenatal counselling to attitude and good breast feeding practises in post-natal mothers. Though high percentage of educated women living in nuclear families followed good breast feeding practises it was not statistically significant. 


\section{Discussion}

Breast feeding is a natural means of providing nutrition for growth and development of infants. But its practice is influenced by maternal knowledge, attitude, employment, family support and other related factors. In our study about $61 \%$ were from middle socioeconomic group and majority of mothers belonged to Hindu religion (86.67\%). A Ekanam et al study also shows similar result as $52 \%$ from middle socioeconomic group but majority belonged to Christian religion.

It may be because of geographical difference in population [11]. Majority (71\%) mothers of our study population were house wives. Previous studies also showed most of the mother were house wives $(94 \%$, $57 \%$ ) in their study [12]. Up to $93 \%$ of study population had antenatal counselling regarding breast feeding and most of them through doctors $(45.91 \%)$. This is more than the previous study [13] in which $70 \%$ were antenatally counselled denoting increased public awareness and also access to health facilities at every level.

About $80 \%$ of mothers who participated in our study were likely to practise exclusive breast feeding. This is in agreement with the previous study done by Mehdi \& Mahanta on breastfeeding and weaning practices which had, exclusive breast feeding rate of $69.35 \%$ [14]. According to UNICEF 2008-2012 data exclusive breast feeding in India is $46.5 \%$. Higher rate in our study is because the study is hospital based. Colostrum is the first phase of breast milk produced after delivery and recent scientific researchers have shown that besides being the best food for newborn it is also immuno augmenter. In our study we found that $92 \%$ know about colostrum.

This is not in concurrence with the previous study done by Ben Slama, et al [15] who reported that $43 \%$ of mothers did not know about colostrum. Bahl et al. [16] and Vimla et al. [17] who reported that $91.7 \%$ and $100 \%$ of mothers practiced colostrum feeding respectively indicate that there is increased awareness among mothers about colostrum. Kumar D et al [18] also reported that the knowledge and practise with respect to colostrum was good in about $88 \%$ of mothers. In our study, we found that the $14 \%$ babies were fed with prelacteal feeds. This is similar to Udgiri $\mathrm{R}$ et al, a hospital based study which showed that $13 \%$ of the babies were fed with prelacteal feeds like honey and sugar water [19]. But there was a higher rate (41\%) of pre lacteal feeding in the Manas Pritham et al study [20]. This was probably because that study included the mothers from economically challenged group and also both hospital and home deliveries were included in the study. Around $88 \%$ of mothers in our study were aware of right position of breast feeding only about $58 \%$ in the Kumar A, et al [27] study were aware of the correct position. This difference is because the latter study included only primi parous mothers. In our study, more than fifty percent of the women had positive attitude towards breastfeeding. Studies have found a direct correlation of positive attitude with optimal exclusive breast feeding practice $[21,22,23]$. Positive parental attitudes towards infant feeding are reported tobe an important component in child nutritional health [24].

In the study conducted by Girish S, et al, on primi para mother's knowledge, attitude and practice of breastfeeding, it was found that the $92 \%$ of mothers had inadequate knowledge regarding time of initiation of breastfeeding and $38 \%$ of mothers had inadequate knowledge about duration of exclusive breastfeeding [25]. In our study $62 \%$ of mothers have knowledge about initiation of breast feeding. Early initiation of breastfeeding (within 4 hours after delivery) was found in $63 \%$. These findings are similar to that of Kumar D et al [18] where it was 58\%. UNICEF data (2008-2012) for India regarding early breast feeding initiation is $41 \%$. The main reason for delay in initiating breast feeding is fatigue and pain of caesarean section, which is in agreement in study done by Shwetal B, et al[26].

According to our study, statistically significant association is seen with antenatal counselling and good breast feeding practises. Higher percentage of educated women from nuclear families had good breast feeding practises, but there was no significant statistical association .Kumar D et al reported a statistically significant association between maternal education and good breast feeding practises.

\section{Conclusion}

In summary, even though majority $(91.6 \%)$ of the respondents are knowledgeable about breast feeding, there is still a gap between the actual practises within the recommended duration. Antenatal counselling and working status were the important variables which show positive association with breast feeding practise. The main factors observed in our study interfering with 
exclusive breastfeeding were post caesarean section fatigue and apprehension that breast milk is not sufficient for the baby. The attitude towards breastfeeding was good in those who had received antenatal counselling. But there was a gap in knowledge, attitude and practise of breast feeding in those who were not counselled antenatally.

Based on the finding of this study, health service organizations have to critically look at the gap between the actual knowledge of breast feeding and the practice done in the area and have to orient service providers at service delivery points. Antenatal counselling is needed to increase the practice of exclusive breast feeding.

Existing antenatal counselling on breastfeeding needs to be strengthened by informing all pregnant women about the benefits of breastfeeding and motivating them by curtailing their ill beliefs regarding breastfeeding and educating them that breast Feeding is the healthiest and safest way to fed babies.

Funding: Nil, Conflict of interest: None initiated, Perission from IRB: Yes

\section{References}

1. Academy of Breastfeeding Medicine: Position on breastfeeding. 2008, http://www.bfmed.org. 10.1089/ bfm. 2008.9988 .

2. United Nations Children's Fund (UNICEF): Tracking progress on child and maternal nutrition: a survival and development priority. Nov 2009, http://www.unicef.org.

3. Heckman JJ: Factors influencing milk production in nursing mothers. 2011, http://child encyclopedia.com

4. Singh K, Srivastava P: The effect of colostrums on infant mortality: urban rural differentials. Health and population. Perspect Issues. 1992 May, 15 (3\&4): 94100.

5. Okolo SN, Ogbonna C: Knowledge, attitude and practice of health workers in Keffi local government hospitals regarding baby-friendly hospital initiative (BFHI) practices. Eur J ClinNutr. 2002 May;56 (5): 438-441. 10.1038/sj.ejcn.1601331.

6. Fergusson DM, Beautrais AL, Silva PA: Breastfeeding and cognitive development in the first seven years of life. SocSci Med. 1982, 16: 1705-1708. 10.1016/0277-9536(82)90096.
7. Furman L, Minch NM, Hack M: Breastfeeding of very low birth weight. J-Hum-Lact. 1998 March 14 (1): 29-34. 10.1177/089033449801400112].

8. World Health Organization (WHO) The global strategy for infant and young child feeding. Geneva: WHO; 2003www.who.int/nutrition/topics /global_ strategy/en.

9. International Institute for Population Sciences. National family health survey (NFHS 3), 2005-06: https://dhsprogram.com/pubs/pdf/FRIND3/ FRIND3-VOL2.

10. UNICEF and world health organization 2003.Global strategy for infant and young child feeding,GenevaSwitzerland.www.who.int/nutrition/publ ications/ infantfeeding/9241562218/en.

11. A. EkanemIA,Ekanem AP, Asuquo A ,Eyo VO Attitude of Working Mothers to Exclusive Breastfeeding in Calabar Municipality, Cross River State, Nigeria. Journal of Food Research. 2012 May; 1(2):71-75. doi:10.5539/jfr.v1n2p71.

12. Chaudhary RN, Shah T, Raja S. Knowledge and practice of mothers regarding breast feeding: a hospital based study.Health Renaissance .2011 Dec; 9 (3); 194200.

13. Jain1, Jyoti,Bala .Knowledge of breastfeeding and breast feeding practises among mothers delivered at teritiary level obstetric care hospital at Udaipur. J Med Pharm Sci. 2013 Sep;4 (1):15.

14. Medhi GK, Mahauta J. Breastfeeding weaning practices and nutritional status of infants of tea gardens of Assam. Indian Pediatr. 2004 June;41:1277-78.

15. Ben Slama F, Ayari I, Buzini F, Belhadj O, Achour $\mathrm{N}$. Exclusive breastfeeding and mixed feedingknowledge, attitudes and practices of primi parous mothers. East Mediterr Health J. 2010 June;16(6): 630-35.

16. Bahl L, Kaushal RK. Infant rearing practices in and Beliefs in rural Inhabitants of Himachal Pradesh. Indian Pediatrics 1987 April; 24:903-906.

17. Vimla V, Ratnaprabha C. Infant feeding practices among Tribal Communities of Andhra Pradesh Indian Pediatrics 1987 Oct; 24: 907. 
Original Research Article

18. Agarwal N, Swami H.Socio-demographic correlates of breast-feeding in urban slums of Chandigarh. Indian J Med Sci. 2006 Nov; 60(11):461-6.

19. Udgiri R, Shashank KJ, Sorganvi V. Breast Feeding Practices Among Postnatal Mothers- A Hospital Based Study. J AdvSci Res. 2015 May;6(1):10-3.

20. Manas,Pratim Roy.Determinants of Pre lacteal Feeding in Rural Northern India. J Prev Med. 2014 May; 5(5): 658-663.

21. Kloeblen-Tarver AS, Thompson NJ, Miner KR. Intent to breast-feed- the impact of attitudes, norms, parity and experience. Am J Health Behav.2002 June; 26:182-187.

22. Hurley KM, Black MM, Papas MA, et al: Variation in breastfeeding behaviours, perceptions, and experiences by race/ethnicity among a low-income state wide sample of special supplemental nutrition program for women, infants and children (WIC) participants in the United States. Matern Child Nutr. 2008 April, 4:95-105.
23. Persad MD, Mensinger JL. Maternal breastfeeding attitudes - association with breast feeding intent and socio-demographics among urban primiparas.J Community Health. 2008 April; 33:53-60.

24. Wojcicki JM, Gugig R, Tran C, Kathiravan S, Holbrook K, Heyman MB: Earlyexclusive breastfeeding and maternal attitudes towards infant feeding in a population of new mothers in San Francisco, California. Breastfeed Med.2010 Feb; 5 (1):9-15.

25. Girish S, Ghandhimathi M. Mother's Knowledge, Attitude and Practice of Breastfeeding. International Journal of Advanced Nursing Science and Practice. 2015 June; 2(1):41-8.

26. Shwetall B, Pooja P, Neha K, Amit D, Rahul P. Knowledge, Attitude and Practice of Postnatal Mothers for Early Initiation of Breast Feeding in the Obstetric Wards of A Tertiary Care Hospital of Vadodara City. National Journal of Community Medicine. 2012 April; 3(2):305-9.

\section{How to cite this article?}

Haricharan K R, Vardhan K, Naidu R. Knowledge, attitude and practise of breast feeding among postnatal mothers at rural tertiary hospital. J PediatrRes.2017;4(02):113-119.doi:10.17511/ijpr.2017.i02.04. 